\title{
SOIL AND PLANT RELATIONS OF SOME ORNITHOGALUM (ENDEMIC/NON ENDEMIC) SPECIES
}

\author{
KARAGÜZEL, Ü. Ö. - ÖZKAN, C. F.* \\ Batı Akdeniz Agricultural Research Institute, Antalya, Turkey \\ *Corresponding author \\ e mail: ummuozgul.karaguzel@tarimorman.gov.tr
}

(Received $31^{\text {st }}$ Oct 2018; accepted $25^{\text {th }}$ Jan 2019)

\begin{abstract}
The study was carried out to determine the soil properties of the Ornithogalum L. species in the West Mediterranean Region of Turkey and their effects on plant morphology. Plant and soil samples concerning species Ornithogalum umbellatum L., O. oligophyllum E.D. Clarke, O. narbonense L., $O$. pyrenaicum L., O. lanceolatum Labill., O. pamphylicum (endemic) O.D. Düşen \& Sümbül, O. montanum Cirillo, O. armeniacum Baker, O. neurostegium Boiss. \& Blanche, O. orthophylum Ten. and $O$. chetikianum (endemic) Uysal, Ertugrul \& Dural were collected from 32 different populations between March and June in 2012. The soils of the plant taxa were textured with sandy loam, loam, silty loam, and sandy clay loam; their EC values were in the range 71-741 $\mu$ mhos $\mathrm{cm}^{-1}$; and their $\mathrm{pH}$ values varied between 6.9 and 8.3. The highest organic matter content was in $O$. orthophylum, whereas the lowest value was in $O$. chetikianum (endemic) and $O$. pamphylicum (endemic). According to the means, the highest values of phosphorus, potassium, calcium, and magnesium were determined in the soil samples belonging to $O$. lanceolatum (106.0 mg kg-1 $)$, O. lanceolatum $\left(657.5 \mathrm{mg} \mathrm{kg}^{-1}\right), O$. montanum $\left(6552 \mathrm{mg} \mathrm{kg}^{-1}\right)$ and $O$. pyrenaicum $(746.8 \mathrm{mg} \mathrm{kg}-1$ ), respectively.
\end{abstract}

Keywords: Ornithogalum, ecology, habitats, soil properties, morphological characters, Turkey

\section{Introduction}

Asparagaceae is a family of flowering plants containing 143 plant genera and 3632 species. The genus Ornithogalum L. is in the family Asparagaceae in the major group Angiosperms. Ornithogalum L. is a perennial plant and is widely distributed in Europe, Asia, Africa and Madagascar. The genus Ornithogalum in tribe Ornithogaleae (Caurel) J.C. Manning \& Goldblatt of subfamily Ornithogaloideae Speta (Hyacinthaceae Batsch) consists of about 200 species of bulbous herbs native to Southern Europe, the Mediterranean basin, and South Africa (Manning et al., 2009; Andric et al., 2015; Aykurt et al., 2016).

The West Mediterranean Region is one of the richest places of Turkey in terms of plant diversity. According to the latest research, there are 54 known Ornithogalum species in the world, with 17 of them being endemic to Turkey. The West Mediterranean Region possesses 18 Ornithogalum species and 5 of them are endemic to the region (Davis, 1988; Düşen and Deniz, 2005; Uysal et al., 2005; Mutlu and Karakuş, 2012).

Ornithogalum species is used for ornamental or medicinal plant and can also be consumed as vegetable (Kamanestsky and Okubo, 2012). There are a number of studies on the taxonomy, cytology, ecology, seed micromorphology (Goldblatt and Manning, 2011; Y1lmaz, G., 2014; Rat et al., 2016; Corominas et al., 2017), and in vitro propagation of Ornithogalum (Yanagawa and Ito, 1988; Nayak and Sen, 1995; Ziv and Lilien-Kipnes, 2000; Kariuki and Kako, 2003; Malabadi and van Staden, 2004; Naik and Nayak, 2005; Ozel and Khawar, 2007). 
Ornithogalum species in Turkey have distribution from 0 to $2600 \mathrm{~m}$ and in the Mediterrenean, Euro Siberian and Iranian Turan phytogeographical region.

To the best of knowledge, there is no study on the natural populations of Ornithogalum with the physical and chemical characteristic concentrations of the soils convenient.

Soil is a key environmental factor for wild plant populations since plant development depends largely on the nutrients of soil. Therefore, soil analyses of wild plant populations may be the means for understanding soil and its possible correlations with plants (Li and Mazza, 1999; Roca-Perez et al., 2004). Several studies showed that microelement contents in plants were affected by not only soil microelement concentrations but also the differences in chemical properties (i.e. $\mathrm{pH}$ and carbonate content) of the soil (Brun et al., 1998; Rapp et al., 1999; Saatçi and Yağmur, 2000; Roca-Perez et al., 2004).

Soil is known to have a significant impact on plants. Knowledge of the physical and chemical properties of soil helps to keep and grow plants effectively, and the use of the type of soil required for a plant will be essential for its faster cultivation and development (Reed, 2011).

The main aim of our study was aimed to determine the interactions between soil and plant properties in different Ornithogalum species growing in the West Mediterranean Region of Turkey, in order to provide information to the future cultivation studies in Ornithogalum species.

\section{Materials and methods}

The study was conducted in 32 populations of 11 Ornithogalum species $(O$. umbellatum L., O. oligophyllum E.C. Clarke, O. narbonense L., O. pyrenaicum L., $O$. lanceolatum Labill., O. pamphylicum O.D. Düsşen \& Sümbül 'endemic', O. montanum Cyr., O. armeniacum Baker, O. neurostegium Boiss. \& Blanche, O. orthophylum Ten., and $O$. chetikianum Uysal, Ertugrul \& Dural 'endemic' located in the West Mediterranean Region of Turkey. Soil samples were collected by means of a garden spade in a depth of $30 \mathrm{~cm}$ after removing the surface litter between March and June in 2012. Details of original locations of collected samples are shown in Figure 1.

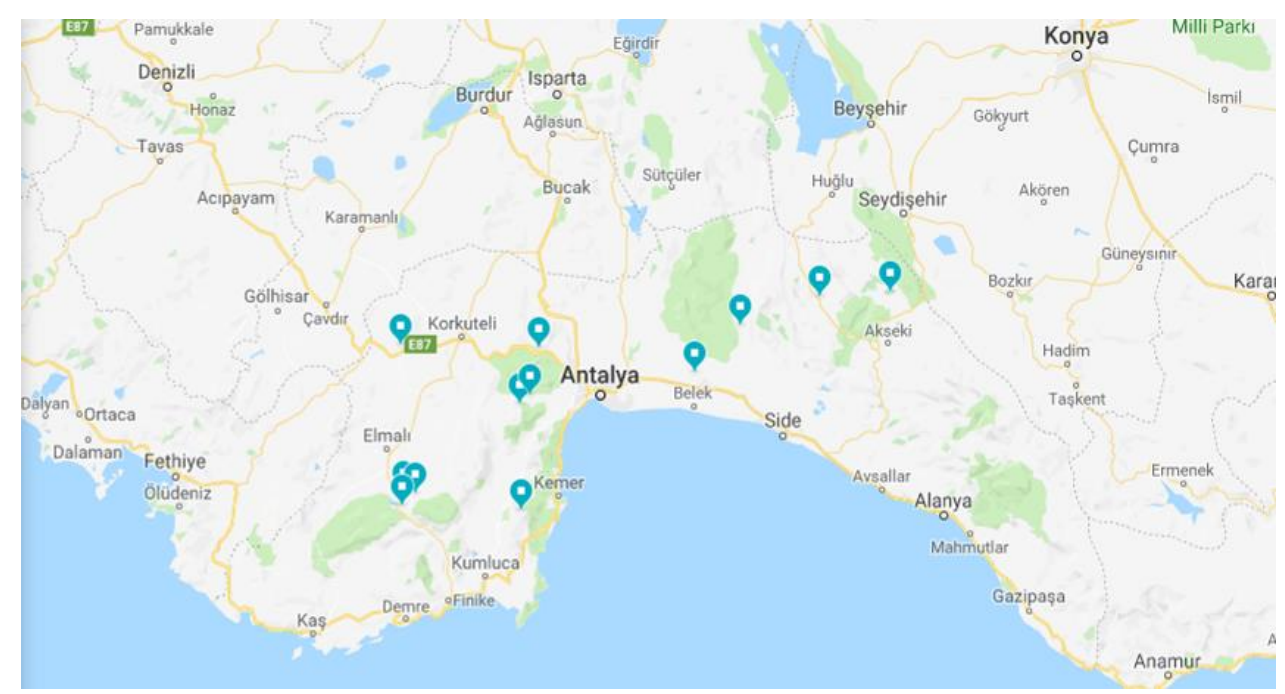

Figure 1. The location of sampling site of Ornithogalum species 
Their appearances of flowering stage of the Ornithogalum species are presented in Figure 2.

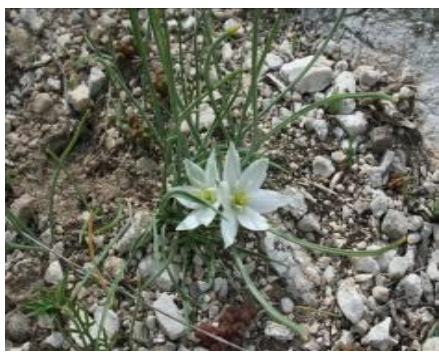

a

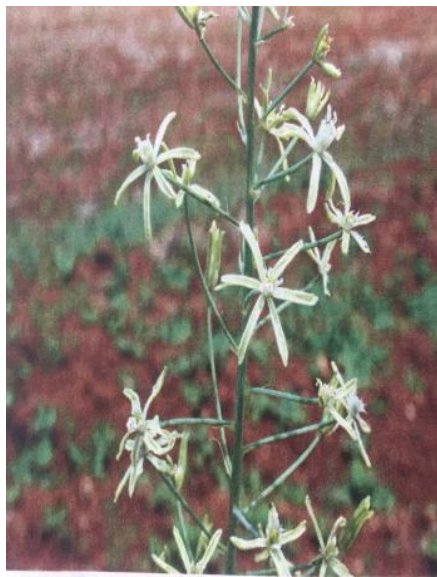

d

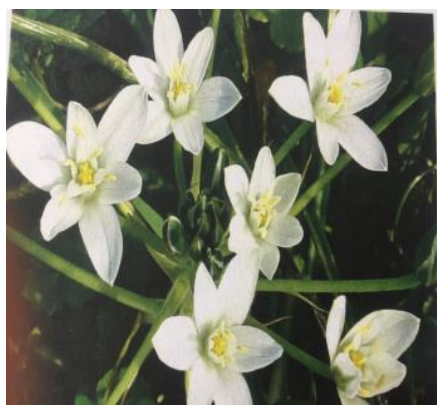

g

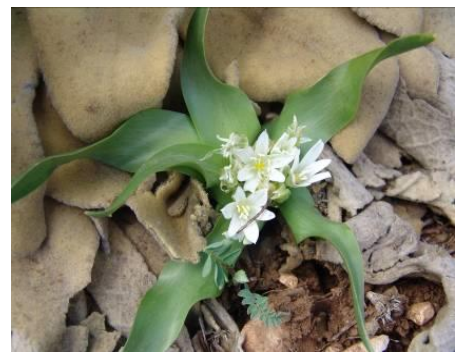

b

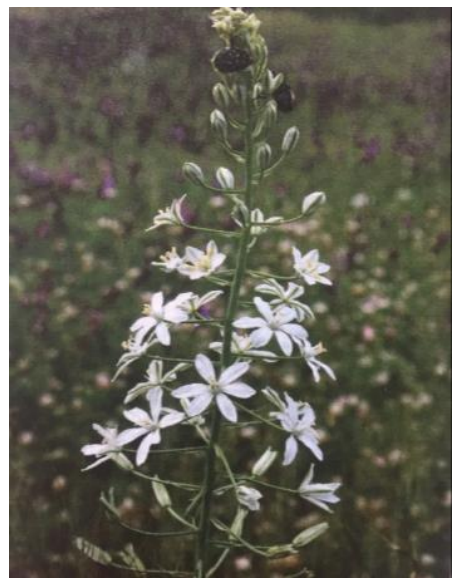

e

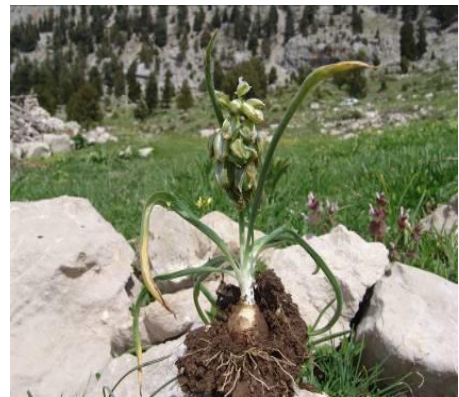

h

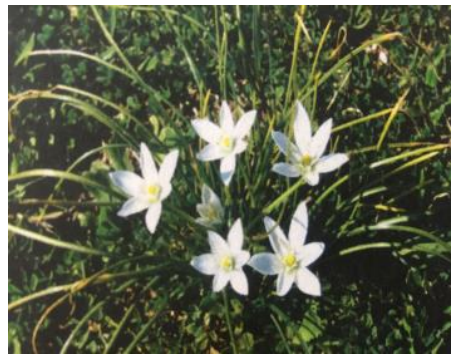

C

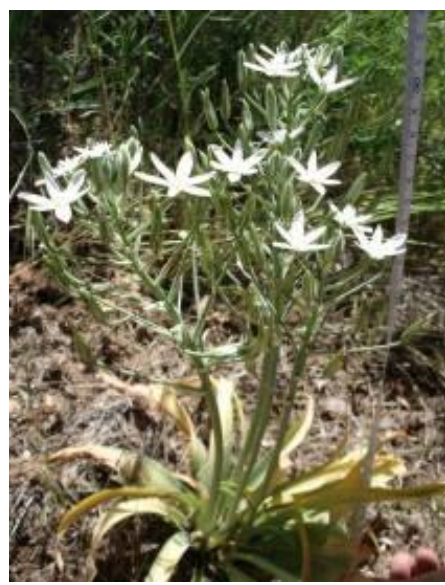

$\mathbf{f}$

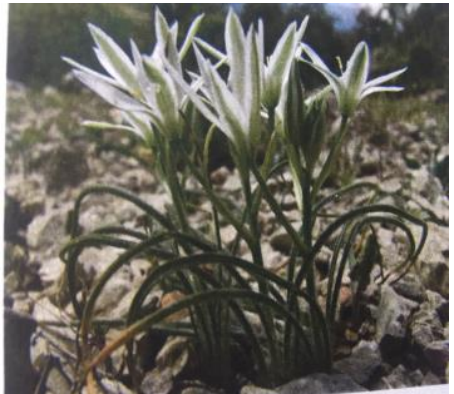

i

Figure 2. Some different genotypes of Ornithogalum species plant sampling flowering period. a $O$. pamphyllicum (endemic), $\boldsymbol{b}$ O. lanceolatum, $\boldsymbol{c}$ O. orthophyllum, $\boldsymbol{d}$ O. pyrenaicum, $\boldsymbol{e} O$. narborense, $\boldsymbol{f} O$. montanum, $\boldsymbol{g} O$. umbellatum, $\boldsymbol{h}$ O. oligophyllum, $\boldsymbol{i}$ O. armeniacum

At every site, four 1000-g soil samples were collected at three randomly selected points from an area of $25 \mathrm{~m}^{2}$, placed in clear plastic bags $(35 \times 25 \mathrm{~cm})$, sealed with a rubber band, and brought to the laboratory. Then, the air-dried soil samples were prepared for the analyses by sifting them through a 2-mm mesh sieve. The analyses were conducted in the soil analysis laboratory of the Bat Akdeniz Agricultural Research Institute (BATEM). The pH (potential of hydrogen-soil reaction) and EC (The Electrical Conductivity) values of the soils were analyzed in a 1:2.5 soil and water mixture, as recommended by Jackson (1967). The organic matter was determined using 
the Walkley-Black method, as suggested by Black (1965). The available P was found with the Olsen method (Olsen and Sommers, 1982). $\mathrm{CaCO}_{3}$ was determined with the Scheibler calcimeter method (Kacar, 2009). The texture of soil was tested with the hydrometer method by Bouyoucos (1951), and the available $\mathrm{K}, \mathrm{Ca}$ and $\mathrm{Mg}$ were found by using $1 \mathrm{~N}$ ammonium acetate extraction suggested by Kacar (2009). All the collected data were subjected to the analysis of variance, and the mean values were compared using Duncan's multiple range tests at the 0.05 level (Gomez and Gomez, 1984).

In the study, morphological characters of the plants such as flowering time (day), length of flower stems ( $\mathrm{mm} / \mathrm{plant}$ ), bulb diameter (number/plant) and the number of flowers (number) were determined according to Martinez-Azorin et al. (2007). Taxonomic description was made according to Davis (1988). Morphologic characters of the five plants belong to each species were measured in natural habitats when the soil samples were collected. All the measurements were done by a compass and analytical balance.

The number of the soil samples varied from 2 to 6 , because the number of location was limited for some species. The number of the soil sample was collected according to the number of location.

\section{Results}

Thirty-two soil samples were collected from different geographical sites distributed throughout the West Mediterranean, Antalya between March and June in 2012. Table 1 presents the soil numbers, localities, habitats, and altitudes, while Table 2 provides some properties of the soils (texture, $\mathrm{pH}, \mathrm{EC}, \mathrm{CaCO} 3$, organic matter, potassium, phosphorus, calcium and magnesium).

Table 1. Soil samples, localities, altitudes and habitats of the Ornithogalum species

\begin{tabular}{|c|c|c|c|c|c|c|}
\hline Species & \begin{tabular}{|c|}
$\begin{array}{c}\text { Soil } \\
\text { number }\end{array}$ \\
\end{tabular} & \begin{tabular}{|c|}
$\begin{array}{c}\text { Date of } \\
\text { collection }\end{array}$ \\
\end{tabular} & Locality & Coordinates & Altitude (m) & Habitat \\
\hline \multirow{2}{*}{ O. pamphylicum } & 1 & 17.04 .2012 & $\begin{array}{l}\text { The Feslikan } \\
\text { Plateau } \\
\text { Sakarpinarı } \\
\end{array}$ & $\begin{array}{l}\text { N } 36.50492 \\
\text { E } 30.24494\end{array}$ & 1787 & $\begin{array}{l}\text { Stony, rocky, and } \\
\text { limestone slopes }\end{array}$ \\
\hline & 2 & 12.04 .2012 & $\begin{array}{c}\text { Çığlıkara Forest, } \\
\text { Elmalı }\end{array}$ & $\begin{array}{l}\text { N } 36.52530 \\
\text { E } 29.82927 \\
\end{array}$ & 1782 & $\begin{array}{c}\text { Stony and rocky } \\
\text { areas }\end{array}$ \\
\hline \multirow[t]{2}{*}{ O. lanceolatum } & 3 & 14.04 .2012 & $\begin{array}{c}\text { Sedir Research } \\
\text { Forest Road, } \\
\text { Elmalı } \\
\end{array}$ & $\begin{array}{l}\text { N } 36.35215 \\
\text { E } 30.01264\end{array}$ & 1593 & $\begin{array}{c}\text { Ground water } \\
\text { withdrawal, } \\
\text { meadows } \\
\end{array}$ \\
\hline & 4 & 10.04 .2012 & $\begin{array}{l}\text { Sedir Research } \\
\text { Forest, Elmalı } \\
\end{array}$ & $\begin{array}{l}\text { N } 36.36023 \\
\text { E } 29.57353 \\
\end{array}$ & 1350 & Rocky slopes \\
\hline \multirow{2}{*}{ O. orthophyllum } & 5 & 14.04 .2012 & $\begin{array}{c}\text { Entrance of the } \\
\text { Yenice Village, } \\
\text { Old Korkuteli } \\
\text { Road }\end{array}$ & $\begin{array}{l}\text { N } 37.00433 \\
\text { E } 30.29021\end{array}$ & 402 & $\begin{array}{c}\text { Road side and the } \\
\text { rocky and } \\
\text { limestone area }\end{array}$ \\
\hline & 6 & 20.03 .2012 & \begin{tabular}{|c|} 
Akdeniz \\
University \\
Health Sciences \\
School \\
\end{tabular} & $\begin{array}{l}\text { N } 36.53497 \\
\text { E } 30.39151\end{array}$ & 35 & $\begin{array}{l}\text { Road side and } \\
\text { macquis groves }\end{array}$ \\
\hline O. armeniacum & 7 & 09.04.2012 & $\begin{array}{c}\text { The Çakıllı } \\
\text { Passage, } \\
\text { Cevizli, Akseki } \\
\end{array}$ & $\begin{array}{l}\text { N } 37.10287 \\
\text { E } 37.04368\end{array}$ & 1210 & $\begin{array}{c}\text { Macquis groves as } \\
\text { well as Rocky and } \\
\text { limestone areas }\end{array}$ \\
\hline
\end{tabular}




\begin{tabular}{|c|c|c|c|c|c|c|}
\hline & 8 & 21.04 .2012 & $\begin{array}{c}\text { The Ormana } \\
\text { Village, İbrad } 1 \\
\end{array}$ & $\begin{array}{l}\text { N } 37.04368 \\
\text { E } 31.35383 \\
\end{array}$ & 978 & $\begin{array}{c}\text { Rocky and } \\
\text { limestone areas }\end{array}$ \\
\hline & 9 & 22.05 .2012 & $\begin{array}{l}\text { Köprülü } \\
\text { Canyon, } \\
\text { Manavgat }\end{array}$ & $\begin{array}{l}\text { N } 37.14490 \\
\text { E } 31.06435\end{array}$ & 1468 & Rocky areas \\
\hline & 10 & 14.04 .2012 & $\begin{array}{c}\text { Sedir Research } \\
\text { Forest, Elmalı }\end{array}$ & $\begin{array}{l}\text { N } 36.36023 \\
\text { E } 29.57353 \\
\end{array}$ & 1089 & $\begin{array}{c}\text { Macquis groves } \\
\text { and stony area }\end{array}$ \\
\hline & 11 & 01.05 .2012 & $\begin{array}{c}\text { The Serinyaka } \\
\text { Village, } \\
\text { Gündoğmuş }\end{array}$ & $\begin{array}{l}\text { N } 36.47351 \\
\text { E } 31.49572\end{array}$ & 620 & $\begin{array}{l}\text { Stony and rocky } \\
\text { slopes }\end{array}$ \\
\hline & 12 & 15.04 .2012 & Hisarönü, İbrad 1 & $\begin{array}{l}\text { N } 37.05503 \\
\text { E } 31.36025 \\
\end{array}$ & 1075 & $\begin{array}{c}\text { Rocky and humid } \\
\text { area }\end{array}$ \\
\hline \multirow{2}{*}{ O. neurostegium } & 13 & 14.04 .2012 & $\begin{array}{l}6 \mathrm{~km} \text { from } \\
\text { Korkuteli to } \\
\text { Kizilcadağ }\end{array}$ & $\begin{array}{l}\text { N } 37.01023 \\
\text { E } 29.58256\end{array}$ & 663 & $\begin{array}{l}\text { Limestone and } \\
\text { stony slopes }\end{array}$ \\
\hline & 14 & 14.04 .2012 & $\begin{array}{c}\text { Between } \\
\text { Korkuteli and } \\
\text { Elmalı Road }\end{array}$ & $\begin{array}{l}\text { N } 36.480172 \\
\text { E } 30.007571\end{array}$ & 1231 & $\begin{array}{l}\text { Road side and } \\
\text { open field }\end{array}$ \\
\hline \multirow{2}{*}{ O. umbellatum } & 15 & 21.04 .2012 & $\begin{array}{c}\text { The Burmahanc1 } \\
\text { Village, Serik }\end{array}$ & $\begin{array}{l}\text { N } 36.56288 \\
\text { E } 31.03501 \\
\end{array}$ & 15 & Humid meadows \\
\hline & 16 & 09.04.2012 & $\begin{array}{c}\text { Akseki Ömer } \\
\text { Duruk Facility }\end{array}$ & $\begin{array}{l}\text { N } 36.998694 \\
\text { E } 31.759739 \\
\end{array}$ & 1100 & $\begin{array}{c}\text { Road side humid } \\
\text { area }\end{array}$ \\
\hline \multirow[b]{2}{*}{ O. montanum } & 17 & 14.04 .2012 & $\begin{array}{c}\text { Sedir Research } \\
\text { Forest Road, } \\
\text { Elmalı }\end{array}$ & $\begin{array}{l}\text { N } 36.35285 \\
\text { E } 29.58350\end{array}$ & 1273 & $\begin{array}{c}\text { Macquis groves } \\
\text { and limestone and } \\
\text { stony area }\end{array}$ \\
\hline & 18 & 14.04 .2012 & $\begin{array}{l}\text { Between Elmalı } \\
\text { and Finike Road }\end{array}$ & $\begin{array}{l}\text { N } 40.46678 \\
\text { E } 36.23239\end{array}$ & 849 & $\begin{array}{l}\text { Rocky and stony } \\
\text { area as well as } \\
\text { under the } \\
\text { Juniperus }\end{array}$ \\
\hline \multirow{2}{*}{ O. chetikianum } & 19 & 24.05 .2012 & $\begin{array}{c}\text { The Feslikan } \\
\text { Plateau }\end{array}$ & $\begin{array}{l}\text { N } 36.48588 \\
\text { E } 30.22266\end{array}$ & 2016 & $\begin{array}{l}\text { Road side, slopes } \\
\text { as well as sandy } \\
\text { and open area }\end{array}$ \\
\hline & 20 & 15.05 .2012 & \begin{tabular}{|} 
Above Feslikan \\
Plateau, \\
Sakarpınarı \\
\end{tabular} & $\begin{array}{l}\text { N } 36.49413 \\
\text { E } 30.24328\end{array}$ & 1850 & Open slopes \\
\hline \multirow{4}{*}{ O. pyrenaicum } & 21 & 14.04 .2012 & $\begin{array}{c}\text { The Göltarla } \\
\text { Village, Elmalı }\end{array}$ & $\begin{array}{l}\text { N } 36.33197 \\
\text { E } 29.58208 \\
\end{array}$ & 1172 & $\begin{array}{c}\text { Slope and macquis } \\
\text { groves }\end{array}$ \\
\hline & 22 & 20.04.2012 & Çiralı Kemer & $\begin{array}{l}\mathrm{N} 40.21440 \\
\mathrm{E} 36.27147 \\
\end{array}$ & 10 & $\begin{array}{c}\text { Sandy and } \\
\text { macquis groves }\end{array}$ \\
\hline & 23 & 17.04 .2012 & $\begin{array}{c}\text { Mt. Tahtalı, } \\
\text { Tekirova }\end{array}$ & $\begin{array}{l}\text { N } 36.32274 \\
\text { E } 30.25091\end{array}$ & 649 & $\begin{array}{l}\text { Road side and } \\
\text { under the pine } \\
\text { forest }\end{array}$ \\
\hline & 24 & 14.04 .2012 & $\begin{array}{c}\text { Yukarı } \\
\text { Karaman, } \\
\text { Korkuteli }\end{array}$ & $\begin{array}{l}\text { N } 37.06781 \\
\text { E } 30.04358\end{array}$ & 1500 & Field side \\
\hline \multirow{3}{*}{ O. narbonense } & 25 & 17.04.2012 & $\begin{array}{c}\text { Entrance of the } \\
\text { Altınbeşik Cave, } \\
\text { Manavgat }\end{array}$ & $\begin{array}{l}\text { N } 37.02188 \\
\text { E } 31.37312\end{array}$ & 645 & $\begin{array}{c}\text { Rocky and } \\
\text { limestone slopes }\end{array}$ \\
\hline & 26 & 09.04 .2012 & \begin{tabular}{|c|} 
The Çakıllı \\
Passage, \\
Cevizli, Akseki \\
\end{tabular} & $\begin{array}{l}\text { N } 37.10287 \\
\text { E } 31.47583\end{array}$ & 1210 & $\begin{array}{l}\text { Roadside, humid, } \\
\text { limestone area }\end{array}$ \\
\hline & 27 & 20.04 .2012 & $\begin{array}{c}\text { The Ovacık } \\
\text { Plateau, Kemer }\end{array}$ & $\begin{array}{l}\text { N } 36.38153 \\
\text { E } 30.25331 \\
\end{array}$ & 1080 & $\begin{array}{l}\text { Open flat } \\
\text { meadows }\end{array}$ \\
\hline
\end{tabular}




\begin{tabular}{|c|c|c|c|c|c|c|}
\hline & 28 & 24.05.2012 & $\begin{array}{l}\text { Mountain } \\
\text { Tahtal1, } \\
\text { Tekirova } \\
\end{array}$ & $\begin{array}{l}\text { N } 36.32274 \\
\text { E } 30.25091\end{array}$ & 645 & $\begin{array}{l}\text { Road side and } \\
\text { under the pine } \\
\text { forest }\end{array}$ \\
\hline & 29 & 14.05 .2012 & $\begin{array}{c}\text { Akdeniz } \\
\text { University } \\
\text { Health Sciences } \\
\text { School }\end{array}$ & $\begin{array}{l}\text { N } 36.53528 \\
\text { E } 30.39529\end{array}$ & 49 & $\begin{array}{l}\text { Road side and } \\
\text { macquis groves }\end{array}$ \\
\hline & 30 & 15.05 .2012 & $\begin{array}{c}\text { Yukarı } \\
\text { Karaman, } \\
\text { Korkuteli }\end{array}$ & $\begin{array}{l}\text { N } 37.06781 \\
\text { E } 30.04358\end{array}$ & 1500 & Field side \\
\hline \multirow[t]{2}{*}{ O. oligophyllum } & 31 & 15.04 .2012 & $\begin{array}{l}\text { The Gembos } \\
\text { Plateau } \\
\text { (Karamuklu), } \\
\text { İbrad } 1\end{array}$ & $\begin{array}{l}\text { N } 37.12381 \\
\text { E } 31.29384\end{array}$ & 1478 & $\begin{array}{l}\text { Humid, open } \\
\text { slopes }\end{array}$ \\
\hline & 32 & 27.04 .2012 & $\begin{array}{l}\text { The Ormana } \\
\text { Village, İbradı }\end{array}$ & $\begin{array}{l}\text { N } 37.04368 \\
\text { E } 31.35383\end{array}$ & 978 & Rocky slopes \\
\hline
\end{tabular}

Table 2. Some physical and chemical properties of the soils where the Ornithogalum species were grown

\begin{tabular}{|c|c|c|c|c|c|c|c|c|c|c|}
\hline Species & 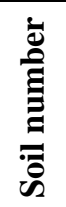 & 珶 & 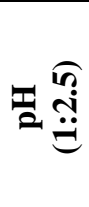 & 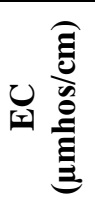 & $\underbrace{\infty}_{0} \underset{0}{a}$ & 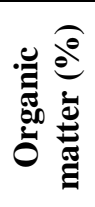 & 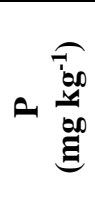 & 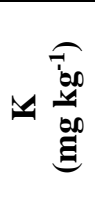 & שَ & 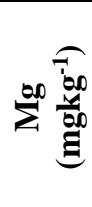 \\
\hline \multirow{2}{*}{ O. pamphylicum } & 1 & $\begin{array}{c}\text { Sandy } \\
\text { loam }\end{array}$ & 8.1 & 210 & 47.0 & 4.2 & 19 & 85 & 1.870 & 689 \\
\hline & 2 & $\begin{array}{c}\text { Sandy } \\
\text { loam }\end{array}$ & 8.0 & 214 & 52.0 & 4.5 & 22 & 75 & 1.780 & 695 \\
\hline \multirow{2}{*}{ O. lanceolatum } & 3 & Loam & 7.8 & 216 & 1.8 & 5.9 & 104 & 661 & 4.426 & 365 \\
\hline & 4 & Loam & 7.8 & 225 & 1.9 & 5.2 & 108 & 654 & 4.342 & 380 \\
\hline \multirow{2}{*}{ O. orthophyllum } & 5 & $\begin{array}{c}\text { Sandy } \\
\text { loam }\end{array}$ & 7.8 & 363 & 13.8 & 11.6 & 89 & 481 & 5.089 & 430 \\
\hline & 6 & $\begin{array}{c}\text { Sandy } \\
\text { loam }\end{array}$ & 7.9 & 380 & 11.2 & 10.8 & 84 & 456 & 5.123 & 445 \\
\hline \multirow{6}{*}{ O. armeniacum } & 7 & Loam & 7.9 & 108 & 2.6 & 3.9 & 5 & 152 & 4.032 & 327 \\
\hline & 8 & Loam & 8.0 & 104 & 2.6 & 4.8 & 53 & 205 & 5.880 & 112 \\
\hline & 9 & $\begin{array}{c}\text { Sandy } \\
\text { loam }\end{array}$ & 6.9 & 741 & 1.8 & 13.2 & 211 & 799 & 4.241 & 1.232 \\
\hline & 10 & Loam & 7.6 & 196 & 5.4 & 5.1 & 21 & 515 & 9.030 & 226 \\
\hline & 11 & $\begin{array}{c}\text { Sandy } \\
\text { loam }\end{array}$ & 8.3 & 96 & 2.0 & 2.1 & 3.2 & 62 & 2.320 & 93 \\
\hline & 12 & Loam & 7.9 & 147 & 23.1 & 4.8 & 53 & 205 & 5.880 & 112 \\
\hline \multirow[t]{2}{*}{ O. neurostegium } & 13 & $\begin{array}{c}\text { Sandy } \\
\text { loam }\end{array}$ & 8.2 & 187 & 4.1 & 4.1 & 24 & 436 & 5.698 & 542 \\
\hline & 14 & Loam & 7.8 & 419 & 16.4 & 12.6 & 118 & 607 & 4.978 & 391 \\
\hline \multirow[t]{2}{*}{ O. umbellatum } & 15 & $\begin{array}{c}\text { Sandy } \\
\text { loam }\end{array}$ & 8.2 & 256 & 33.3 & 1.8 & 16 & 178 & 2.899 & 265 \\
\hline & 16 & Loam & 7.6 & 310 & 10.2 & 7.6 & 145 & 718 & 5.429 & 336 \\
\hline \multirow{2}{*}{ O. montanum } & 17 & Loam & 7.8 & 419 & 16.4 & 12.6 & 118 & 607 & 4.978 & 391 \\
\hline & 18 & Loam & 7.8 & 142 & 10.0 & 1.6 & 28 & 275 & 8.127 & 210 \\
\hline O. chetikianum & 19 & Sandy & 8.0 & 187 & 2.6 & 2.4 & 16 & 92 & 4.468 & 391 \\
\hline
\end{tabular}




\begin{tabular}{l|c|c|c|c|c|c|c|c|c|c}
\hline & & loam & & & & & & & & \\
\cline { 2 - 11 } & 20 & $\begin{array}{c}\text { Sandy } \\
\text { loam }\end{array}$ & 8.1 & 212 & 2.8 & 2.9 & 25 & 100 & 4.325 & 386 \\
\hline \multirow{5}{*}{ O. pyrenaicum } & 21 & $\begin{array}{c}\text { Silty } \\
\text { loam }\end{array}$ & 7.9 & 196 & 1.8 & 8.3 & 25 & 453 & 4.735 & 420 \\
\cline { 2 - 11 } & 22 & Loam & 7.1 & 143 & 1.7 & 10 & 7 & 178 & 3.381 & 1.690 \\
\cline { 2 - 11 } & 23 & $\begin{array}{c}\text { Silty } \\
\text { loam }\end{array}$ & 7.9 & 120 & 2.3 & 4.3 & 7 & 257 & 8.190 & 470 \\
\cline { 2 - 11 } & 24 & $\begin{array}{c}\text { Silty } \\
\text { loam }\end{array}$ & 7.9 & 108 & 2.9 & 1.4 & 40 & 723 & 7.878 & 407 \\
\hline & 25 & $\begin{array}{c}\text { Sandy } \\
\text { loam }\end{array}$ & 7.3 & 685 & 5.2 & 13.1 & 111 & 276 & 4.736 & 381 \\
\cline { 2 - 11 } & 26 & Loam & 7.3 & 71 & 2.3 & 3.9 & 5 & 152 & 4.032 & 327 \\
\cline { 2 - 10 } & 27 & Loam & 7.3 & 78 & 2.4 & 3.6 & 8 & 165 & 4.535 & 342 \\
\cline { 2 - 10 } & 28 & $\begin{array}{c}\text { Sandy } \\
\text { clay }\end{array}$ & 7.9 & 120 & 2.3 & 4.3 & 7 & 257 & 8.195 & 470 \\
\cline { 2 - 10 } & 29 & $\begin{array}{c}\text { Sandy } \\
\text { loam }\end{array}$ & 8.1 & 160 & 22.2 & 3.6 & 13 & 183 & 4.970 & 427 \\
\cline { 2 - 10 } & 30 & $\begin{array}{c}\text { Silty } \\
\text { loam }\end{array}$ & 7.9 & 108 & 2.9 & 1.2 & 40 & 723 & 7.880 & 407 \\
\hline \multirow{5}{*}{ O. oligophyllum } & 31 & $\begin{array}{c}\text { Sandy } \\
\text { loam }\end{array}$ & 7.2 & 709 & 2.3 & 13.3 & 48 & 288 & 5.020 & 515 \\
\cline { 2 - 10 } & 32 & $\begin{array}{c}\text { Sandy } \\
\text { clay }\end{array}$ & 8.0 & 104 & 2.6 & 4.8 & 53 & 205 & 5.880 & 112 \\
\hline
\end{tabular}

Ornithogalums are usually grown in open meadows, roadside or limestone rocky slopes. Their altitude ranges from $15 \mathrm{~m}$ to $2016 \mathrm{~m}$. The flowers are generally starched, petals are green striped and there are 2-20 flowers. Flower stem lengths vary between 2$45 \mathrm{~cm}$. Leaves are thin or long strip, linear or thick-fleshy, with bright dark green or matte gray-green colors, bulbs of different sizes (small to medium-large) are round or ovoid (Table 3).

Table 3. Morphological characters of natural Ornithogalum species

\begin{tabular}{|c|c|c|c|c|c|}
\hline Species & $\begin{array}{c}\text { Bulb size- } \\
\text { average bulb } \\
\text { diameter }(\mathrm{mm})\end{array}$ & $\begin{array}{c}\text { Leaf } \\
\text { characteristics }\end{array}$ & $\begin{array}{c}\text { Average number of } \\
\text { flowers per } \\
\text { inflorescence } \\
\text { (number) }\end{array}$ & $\begin{array}{l}\text { Stem length } \\
\text { (mm/plant) }\end{array}$ & $\begin{array}{c}\text { Flowering } \\
\text { time }\end{array}$ \\
\hline O. pamphylicum & $\begin{array}{l}\text { Small, long- } \\
\text { ovoid-6.5 }\end{array}$ & Thin long strip & $2-2.5$ & $70-80$ & Mid May \\
\hline O. lanceolatum & Big ovoid-26.7 & $\begin{array}{c}\text { Thick fleshy } \\
\text { bright dark green }\end{array}$ & 2 & $20-30$ & Mid April \\
\hline O. orthophyllum & Small round-10.8 & Quite thin & $2.67-3.00$ & $50-100$ & March \\
\hline O. armeniacum & $\begin{array}{c}\text { Medium round- } \\
17.0 \\
\end{array}$ & Thin & $4.5-6.00$ & $100-250$ & $\begin{array}{c}\text { April-early } \\
\text { May }\end{array}$ \\
\hline O. neurostegium & $\begin{array}{c}\text { Medium long } \\
\text { ovoid-18.7 }\end{array}$ & Thin & $5.63-6.63$ & $200-250$ & Mid May \\
\hline O. umbellatum & \begin{tabular}{|} 
Numerous \\
number of tooth \\
shaped bulblet, \\
Medium Round- \\
18.3
\end{tabular} & Thin & $12.00-18.00$ & $100-200$ & Mid March \\
\hline
\end{tabular}




\begin{tabular}{c|c|c|c|c|c}
\hline O. montanum & Big round-24.3 & $\begin{array}{c}\text { Thick fleshy } \\
\text { matte gray-green }\end{array}$ & $9.79-13.00$ & $100-250$ & End of April \\
\hline O. chetikianum & $\begin{array}{c}\text { Numerous } \\
\text { bulblet, Medium, } \\
\text { Round-18.8 }\end{array}$ & Thick & $7.17-9.13$ & $200-300$ & Early May \\
\hline O. pyrenaicum & Small ovoid-17.2 & Thin long strip & $17.93-21.75$ & $300-450$ & $\begin{array}{c}\text { Mid May-end } \\
\text { of May }\end{array}$ \\
\hline O. narbonense & Big round-22.8 & $\begin{array}{c}\text { Thin linear matte } \\
\text { gray-green }\end{array}$ & $52.00-57.33$ & $250-350$ & $\begin{array}{c}\text { End of April- } \\
\text { end of May }\end{array}$ \\
\hline O. oligophyllum & Small round-12.7 & Thick & $8.00-9.25$ & $100-150$ & $\begin{array}{c}\text { Mid March- } \\
\text { end of March }\end{array}$ \\
\hline
\end{tabular}

Statistical analyses of the results for the soil analyses and the soil classes of the Ornithogalum species are shown in Tables 4 and 5, respectively.

The soil analyses results are also shown in graphs (Fig. $3 a-h)$. Some evaluations and interpretations of the soil analysis results are provided in detail below.

Table 4. Results of the statistical analyses (Mean $\pm S E$ and minimum-maximum) on the soils of Ornithogalum species

\begin{tabular}{|c|c|c|c|c|c|c|c|c|c|}
\hline \multirow[t]{2}{*}{ Species } & \multirow[t]{2}{*}{$\mathbf{N}$} & $\underset{(1: 2.5)}{\text { pH }}$ & $\begin{array}{c}\text { EC } \\
(\mu \mathrm{mhos} / \mathrm{cm})\end{array}$ & $\begin{array}{c}\mathrm{CaCO}_{3} \\
(\%)\end{array}$ & $\begin{array}{c}\text { Organic } \\
\text { matter } \\
\%\end{array}$ & $\begin{array}{c}\mathbf{P} \\
\left(\mathbf{m g ~ k g}^{-1}\right)\end{array}$ & $\begin{array}{c}\mathrm{K} \\
\left(\mathrm{mg} \mathrm{kg}^{-1}\right)\end{array}$ & $\begin{array}{c}\mathrm{Ca} \\
\left(\mathrm{mg} \mathrm{kg}^{-1}\right)\end{array}$ & $\begin{array}{c}\mathrm{Mg} \\
\left(\mathrm{mg} \mathrm{kg}^{-1}\right)\end{array}$ \\
\hline & & \multicolumn{8}{|c|}{ Mean \pm SE (Min.-Max.) } \\
\hline O. pamphylicum & 2 & $\begin{array}{l}8.1^{\mathrm{ns}} \pm 0.1 \\
(8.0-8.1)\end{array}$ & $\begin{array}{c}212.0^{\mathrm{ns}} \pm 2.0 \\
(210.0-214.0)\end{array}$ & $\begin{array}{l}49.5 \mathrm{a}^{* *} \pm 2.5 \\
(47.0-52.0)\end{array}$ & $\begin{array}{l}4.4^{\mathrm{ns}} \pm 0.2 \\
(4.2-4.5)\end{array}$ & $\begin{array}{l}20.5^{\mathrm{ns}} \pm 1.5 \\
(19.0-22.0)\end{array}$ & $\begin{array}{l}80.0 b^{* *} \pm 5.0 \\
(75.0-85.0)\end{array}$ & $\begin{array}{l}1825.0 b^{* *} \pm 45.0 \\
(1780.0-1870.0)\end{array}$ & $\begin{array}{c}692.0^{\mathrm{ns}} \pm 3.0 \\
(695.0-689.0)\end{array}$ \\
\hline O. lanceolatum & 2 & $\begin{array}{l}7.8 \pm 0.0 \\
(7.7-7.8)\end{array}$ & $\begin{array}{c}220.5 \pm 4.5 \\
(216.0-225.0)\end{array}$ & $\begin{array}{l}1.9 \mathrm{c} \pm 0.1 \\
(1.8-1.9)\end{array}$ & $\begin{array}{l}5.6 \pm 0.4 \\
(5.2-5.9)\end{array}$ & $\begin{array}{c}106.0 \pm 2.0 \\
(104.0-108.0)\end{array}$ & $\begin{array}{c}657.5 \mathrm{a} \pm 3.5 \\
(654.0-661.0)\end{array}$ & $\begin{array}{l}4384.0 \mathrm{ab} \pm 42.0 \\
(4342.0-4426.0)\end{array}$ & $\begin{array}{c}372.5 \pm 7.5 \\
(365.0-380.0)\end{array}$ \\
\hline O. ortophyllum & 2 & $\begin{array}{c}7.9 \pm 0.1 \\
(7.8-7.9)\end{array}$ & $\begin{array}{c}371.5 \pm 8.5 \\
(363.0-380.0)\end{array}$ & $\begin{array}{l}12.5 \mathrm{bc} \pm 1.3 \\
(11.2-13.8)\end{array}$ & \begin{tabular}{|c|}
$11.2 \pm 0.4$ \\
$(10.8-11.6)$
\end{tabular} & $\begin{array}{c}86.5 \pm 2.5 \\
(84.0-89.0)\end{array}$ & $\begin{array}{l}468.5 \mathrm{ab} \pm 12.5 \\
(456.0-481.0)\end{array}$ & $\begin{array}{l}5106.0 \mathrm{ab} \pm 17.0 \\
(5089.0-5123.0)\end{array}$ & $\begin{array}{c}437.5 \pm 7.5 \\
(430.0-445.0)\end{array}$ \\
\hline O. armeniacum & 6 & $\begin{array}{l}7.8 \pm 0.2 \\
(6.9-8.3)\end{array}$ & $\begin{array}{l}232.0 \pm 102.9 \\
(96.0-741.0)\end{array}$ & $\begin{array}{l}6.3 \mathrm{c} \pm 3.4 \\
(1.8-23.1)\end{array}$ & $\begin{array}{c}5.7 \pm 1.6 \\
(2.1-13.2)\end{array}$ & $\begin{array}{l}57.7 \pm 32.0 \\
(3.2-211.0)\end{array}$ & $\begin{array}{c}323.0 \mathrm{ab} \pm 113.8 \\
(62.0-799.0)\end{array}$ & $\begin{array}{l}5230.5 \mathrm{ab} \pm 933.7 \\
(2320.0-9030.0)\end{array}$ & $\begin{array}{l}350.3 \pm 180.1 \\
(93.0-1232.0)\end{array}$ \\
\hline O. neurostegium & 2 & $\begin{array}{l}8.0 \pm 0.2 \\
(7.8-8.2)\end{array}$ & $\begin{array}{l}303.0 \pm 116.0 \\
(187.0-419.0)\end{array}$ & $\begin{array}{l}10.3 \mathrm{bc} \pm 6.2 \\
(4.1-16.4)\end{array}$ & $\begin{array}{c}8.4 \pm 4.3 \\
(4.1-12.6)\end{array}$ & $\begin{array}{c}71.0 \pm 47.0 \\
(24.0-118.0)\end{array}$ & $\begin{array}{l}521.5 \mathrm{ab} \pm 85.5 \\
(436.0-607.0)\end{array}$ & $\begin{array}{l}5338.0 \mathrm{ab} \pm 360.0 \\
(4978.0-5698.0)\end{array}$ & $\begin{array}{c}466.5 \pm 75.5 \\
(391.0-542.0)\end{array}$ \\
\hline O. umbellatum & 2 & $\begin{array}{l}7.9 \pm 0.3 \\
(7.6-8.2)\end{array}$ & $\begin{array}{c}283.0 \pm 27.0 \\
(256.0-310.0)\end{array}$ & $\begin{array}{l}21.8 \mathrm{~b} \pm 11.6 \\
(10.2-33.3)\end{array}$ & $\begin{array}{l}4.7 \pm 2.9 \\
(1.8-7.6)\end{array}$ & $\begin{array}{c}80.5 \pm 64.5 \\
(16.0-145.0)\end{array}$ & $\begin{array}{l}448.0 \mathrm{ab} \pm 270.0 \\
(178.0-718.0)\end{array}$ & $\begin{array}{c}4164.0 \mathrm{ab} \pm 1265.0 \\
(2899.0-5429.0)\end{array}$ & $\begin{array}{c}300.5 \pm 35.5 \\
(265.0-336.0)\end{array}$ \\
\hline O. montanum & 2 & $\begin{array}{l}7.8 \pm 0.0 \\
(7.7-7.8)\end{array}$ & $\begin{array}{c}280.5 \pm 138.5 \\
(142.0-419.0)\end{array}$ & $\begin{array}{l}13.2 \mathrm{bc} \pm 3.2 \\
(10.0-16.4)\end{array}$ & $\begin{array}{c}7.1 \pm 5.5 \\
(1.6-12.6)\end{array}$ & $\begin{array}{c}73.0 \pm 45.0 \\
(28.0-118.0)\end{array}$ & $\begin{array}{l}441.0 \mathrm{ab} \pm 166.0 \\
(275.0-607.0)\end{array}$ & $\begin{array}{l}6552.5 \mathrm{a} \pm 1574.5 \\
(4978.0-8127.0)\end{array}$ & $\begin{array}{c}300.5 \pm 90.5 \\
(210.0-391.0)\end{array}$ \\
\hline O. chetikianum & 2 & $\begin{array}{l}8.1 \pm 0.1 \\
(8.0-8.1)\end{array}$ & $\begin{array}{c}199.5 \pm 12.5 \\
(187.0-212.0)\end{array}$ & $\begin{array}{l}2.7 \mathrm{c} \pm 0.1 \\
(2.6-2.8)\end{array}$ & $\begin{array}{l}2.7 \mathrm{~b} \pm 0.3 \\
(2.4-2.9)\end{array}$ & $\begin{array}{c}20.5 \pm 4.5 \\
(16.0-25.0)\end{array}$ & $\begin{array}{c}96.0 \mathrm{~b} \pm 4.0 \\
(92.0-100.0)\end{array}$ & $\begin{array}{l}4396.5 \mathrm{ab} \pm 71.5 \\
(4325.0-4468.0)\end{array}$ & $\begin{array}{c}388.5 \pm 2.5 \\
(386.0-391.0)\end{array}$ \\
\hline O. pyrenaicum & 4 & $\begin{array}{l}7.7 \pm 0.2 \\
(7.1-7.9)\end{array}$ & $\begin{array}{c}141.8 \pm 19.5 \\
(143.0-196.0)\end{array}$ & $\begin{array}{l}2.2 \mathrm{c} \pm 0.3 \\
(1.7-2.9)\end{array}$ & $\begin{array}{c}6.0 \pm 1.9 \\
(8.3-10.0)\end{array}$ & $\begin{array}{l}19.8 \pm 8.0 \\
(7.0-40.0)\end{array}$ & $\begin{array}{l}402.8 \mathrm{ab} \pm 121.4 \\
(178.0-723.0)\end{array}$ & $\begin{array}{l}6046.0 \mathrm{a} \pm 1182.3 \\
(3381.0-8190.0)\end{array}$ & $\begin{array}{c}746.8 \pm 314.7 \\
(407.0-1690.0)\end{array}$ \\
\hline O. narbonense & 6 & $\begin{array}{l}7.6 \pm 0.2 \\
(7.3-8.1)\end{array}$ & $\begin{array}{l}203.7 \pm 97.1 \\
(71.0-685.0)\end{array}$ & $\begin{array}{l}6.2 \mathrm{c} \pm 3.2 \\
(2.3-22.2)\end{array}$ & $\begin{array}{c}5.0 \pm 1.7 \\
(1.2-13.1)\end{array}$ & $\begin{array}{l}30.7 \pm 16.9 \\
(5.0-111.0)\end{array}$ & $\begin{array}{l}292.7 \mathrm{ab} \pm 88.5 \\
(152.0-723.0)\end{array}$ & $\begin{array}{l}5723.5 \mathrm{ab} \pm 742.4 \\
(4032.0-8190.0)\end{array}$ & $\begin{array}{c}392.3 \pm 21.9 \\
(327.0-470.0)\end{array}$ \\
\hline O. oligophyllum & 2 & $\begin{array}{l}7.6 \pm 0.4 \\
(7.2-8.0)\end{array}$ & $\begin{array}{l}406.5 \pm 302.5 \\
(104.0-709.0)\end{array}$ & $\begin{array}{l}2.5 \mathrm{c} \pm 0.2 \\
(2.3-2.6)\end{array}$ & $\begin{array}{c}9.1 \pm 4.3 \\
(4.8-13.3)\end{array}$ & $\begin{array}{c}50.5 \pm 2.5 \\
(48.0-53.0)\end{array}$ & $\begin{array}{l}246.5 \mathrm{ab} \pm 41.5 \\
(205.0-288.0)\end{array}$ & $\begin{array}{l}5450.0 \mathrm{ab} \pm 430.0 \\
(5020.0-5880.0)\end{array}$ & $\begin{array}{l}313.5 \pm 201.5 \\
(112.0-515.0)\end{array}$ \\
\hline General & 32 & $\begin{array}{c}7.8 \pm 0.3 \\
(6.9-8.3)\end{array}$ & $\begin{array}{c}241.7 \pm 39.6 \\
(71.0-741.0)\end{array}$ & $\begin{array}{c}9.7 \pm 2.6 \\
(1.7-52.0)\end{array}$ & $\begin{array}{c}6.0 \pm 0.9 \\
(1.2-13.3)\end{array}$ & $\begin{array}{l}50.8 \pm 10.5 \\
(3.2-211.0)\end{array}$ & $\begin{array}{l}350.7 \pm 52.0 \\
(62.0-799.0)\end{array}$ & $\begin{array}{c}5135.6 \pm 484.9 \\
(1780.0-9030.0)\end{array}$ & $\begin{array}{c}437.1 \pm 68.5 \\
(93.0-1690.0)\end{array}$ \\
\hline
\end{tabular}

Mean seperation within columns by Duncan's multiple range test, at 0.05 level

N.S, *,**,***: Non significiant or significiant at $\mathrm{P}<0.05,0.01$ and 0.001 alpha level respectively

${ }^{\mathrm{a}}$ Capitals show the comparison between the averages given vertically (along the column) 
Table 5. Soil classes of the Ornithogalum species

\begin{tabular}{|c|c|c|c|c|c|c|c|c|}
\hline Species & $\begin{array}{c}\text { pH } \\
(1: 2.5)\end{array}$ & $\begin{array}{c}\text { EC } \\
(\mu \mathrm{mhos} / \mathrm{cm})\end{array}$ & $\begin{array}{c}\mathrm{CaCO3} \\
(\%)\end{array}$ & $\begin{array}{c}\text { Organic } \\
\text { matter }(\%)\end{array}$ & $\begin{array}{c}\mathbf{P} \\
\left(\mathrm{mg} \mathrm{kg}^{-1}\right)\end{array}$ & $\begin{array}{c}\mathrm{K} \\
\left(\mathrm{mg} \mathrm{kg}^{-1}\right)\end{array}$ & $\begin{array}{c}\mathrm{Ca} \\
\left(\mathrm{mg} \mathrm{g} \mathrm{g}^{-1}\right)\end{array}$ & $\begin{array}{c}\mathrm{Mg} \\
\left(\mathrm{mg} \mathrm{kg}^{-1}\right)\end{array}$ \\
\hline O. pamphylicum & Alkaline & Non-saline & Excess & Medium & $\begin{array}{l}\text { Medium- } \\
\text { high }\end{array}$ & Medium & Medium & High \\
\hline O. lanceolatum & $\begin{array}{l}\text { Slightly } \\
\text { alkaline }\end{array}$ & Non-saline & Low & High & High & Very high & High & High \\
\hline O. ortophyllum & $\begin{array}{l}\text { Slightly } \\
\text { alkaline }\end{array}$ & Non-saline & Very high & High & High & Very high & High & High \\
\hline O. armeniacum & $\begin{array}{l}\text { Neutral- } \\
\text { alkaline }\end{array}$ & $\begin{array}{l}\text { Non-saline- } \\
\text { very slightly } \\
\text { saline }\end{array}$ & Low-excess & $\begin{array}{l}\text { Medium- } \\
\text { high }\end{array}$ & Low-high & $\begin{array}{c}\text { Low-very } \\
\text { high }\end{array}$ & $\begin{array}{l}\text { Medium- } \\
\text { high }\end{array}$ & High \\
\hline O. neurostegium & $\begin{array}{l}\text { Slightly } \\
\text { alkaline- } \\
\text { alkaline }\end{array}$ & $\begin{array}{l}\text { Non-saline- } \\
\text { very slightly } \\
\text { saline }\end{array}$ & $\begin{array}{l}\text { Medium-very } \\
\text { high }\end{array}$ & $\begin{array}{l}\text { Medium- } \\
\text { high }\end{array}$ & High & Very high & High & High \\
\hline O. umbellatum & $\begin{array}{l}\text { Slightly } \\
\text { alkaline- } \\
\text { alkaline }\end{array}$ & Non-saline & $\begin{array}{l}\text { Very high- } \\
\text { excess }\end{array}$ & Low-high & $\begin{array}{l}\text { Medium- } \\
\text { high }\end{array}$ & $\begin{array}{c}\text { Low-very } \\
\text { high }\end{array}$ & High & High \\
\hline O. montanum & $\begin{array}{l}\text { Slightly } \\
\text { alkaline }\end{array}$ & $\begin{array}{l}\text { Non-saline- } \\
\text { very slightly } \\
\text { saline }\end{array}$ & Very high & Low-high & High & $\begin{array}{l}\text { High-very } \\
\text { high }\end{array}$ & High & High \\
\hline O. chetikianum & Alkaline & Non-saline & Medium & Medium & $\begin{array}{l}\text { Medium- } \\
\text { high }\end{array}$ & Low & High & High \\
\hline O. pyrenaicum & $\begin{array}{l}\text { Slightly } \\
\text { alkaline- } \\
\text { alkaline }\end{array}$ & Non-saline & Medium & Low-High & Low-high & $\begin{array}{c}\text { Low-very } \\
\text { high }\end{array}$ & High & High \\
\hline O. narbonense & $\begin{array}{l}\text { Neutral- } \\
\text { alkaline }\end{array}$ & $\begin{array}{l}\text { Non-saline- } \\
\text { very slightly } \\
\text { saline }\end{array}$ & Low-excess & Low-high & Low-high & $\begin{array}{c}\text { Low-very } \\
\text { high }\end{array}$ & High & High \\
\hline O. oligophyllum & $\begin{array}{l}\text { Slightly } \\
\text { alkaline- } \\
\text { alkaline }\end{array}$ & $\begin{array}{l}\text { Non-saline- } \\
\text { very slightly } \\
\text { saline }\end{array}$ & Low-medium & $\begin{array}{l}\text { Medium- } \\
\text { high }\end{array}$ & High & $\begin{array}{l}\text { Medium- } \\
\text { high }\end{array}$ & High & High \\
\hline General (average) & $\begin{array}{l}\text { Slightly } \\
\text { alkaline }\end{array}$ & Non-saline & High & High & High & Very high & High & High \\
\hline
\end{tabular}

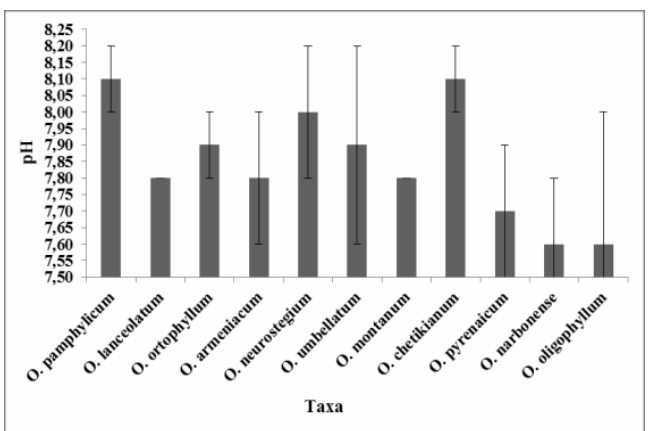

a

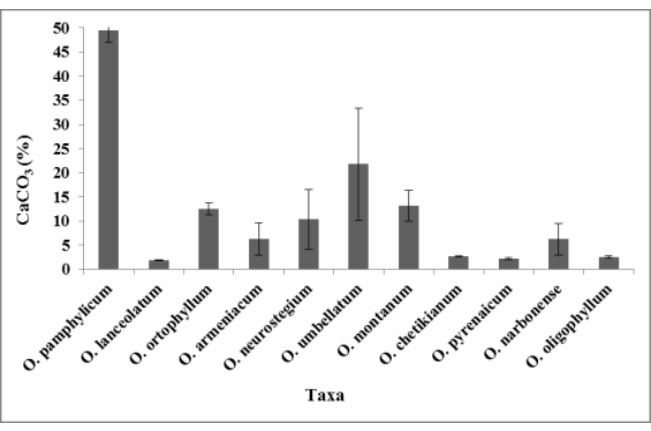

C

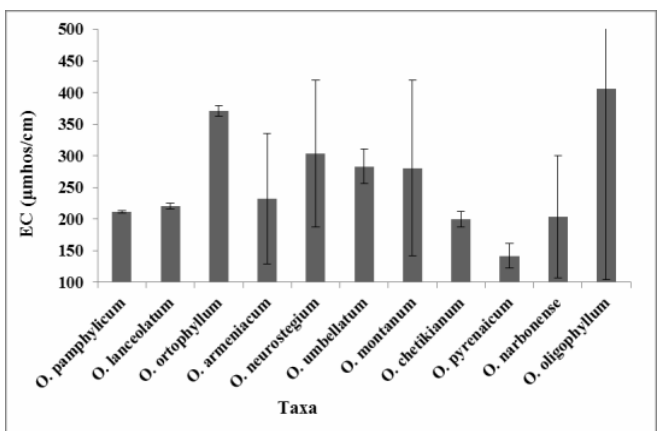

b

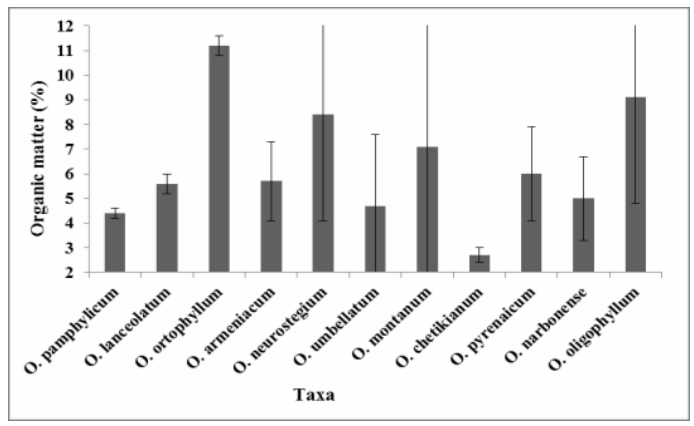

d 


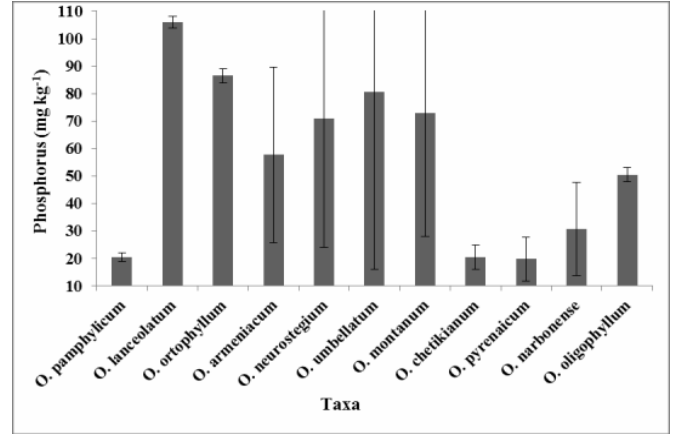

e

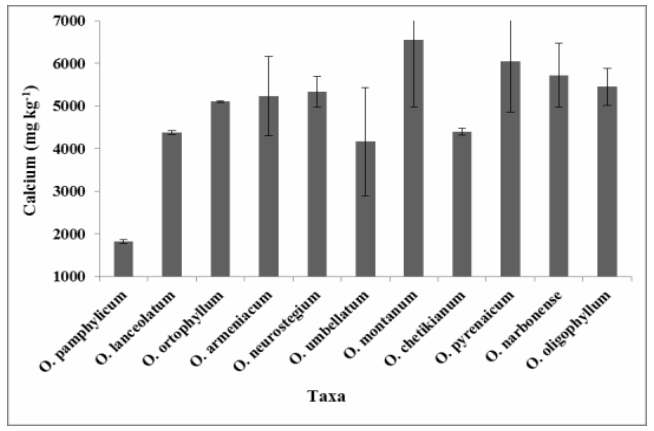

g
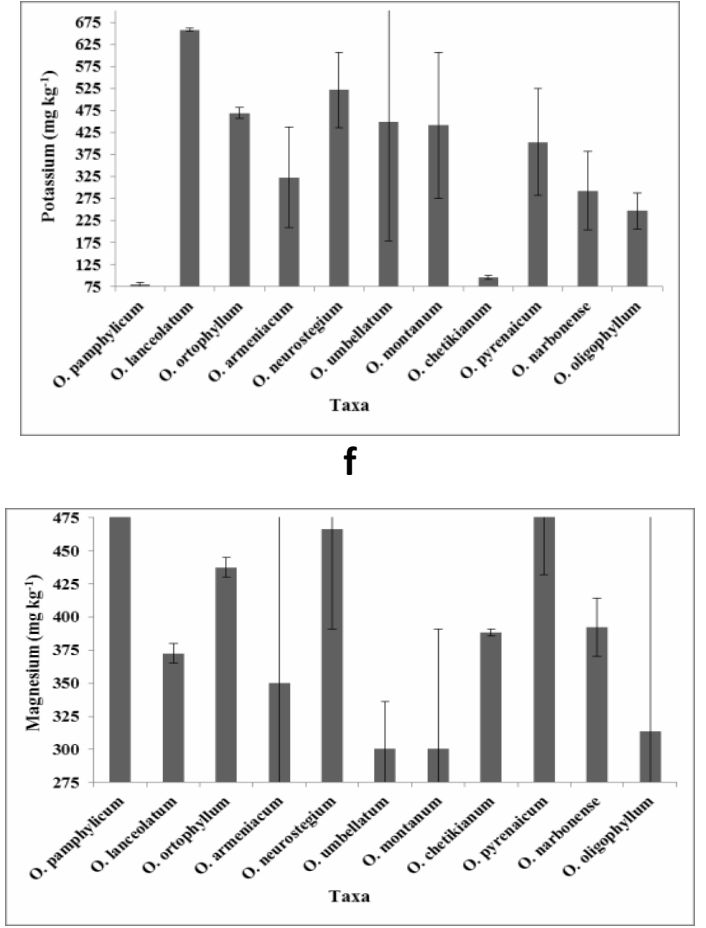

h

Figure 3. a pH values, $\boldsymbol{b}$ EC values, $\boldsymbol{c}$ CaCO3 contents, $\boldsymbol{d}$ organic matter contents, e phosporus contents, $\boldsymbol{f}$ potassium contents, $\boldsymbol{g}$ calcium contents, $\boldsymbol{h}$ magnesium contents

The results indicated that there were no significant differences in $\mathrm{pH}, \mathrm{EC}(\mu \mathrm{mhos} / \mathrm{cm})$, organic matter $(\%)$, phosphorus $\left(\mathrm{mg} \mathrm{kg}^{-1}\right)$ or magnesium $\left(\mathrm{mg} \mathrm{kg}^{-1}\right)$ values among the statistical averages of the soil samples $(\mathrm{P}>0.05)$. Nevertheless, there were significant differences in the $\mathrm{CaCO}_{3}(\%)$, potassium $\left(\mathrm{mg} \mathrm{kg}^{-1}\right)$, and calcium $\left(\mathrm{mg} \mathrm{kg}^{-1}\right)$ values $(\mathrm{P}<$ 0.001) (Table 4). Regarding the soil texture, the species generally grew in the mediumtextured types of soil. The soil samplesof the species were classified as 'loam', 'sandy loam', and 'silty loam' (Table 2). However, Soil Samples 28 (C3: Mt. Tahtal, Tekirova, Antalya) and 32 (C3: The Ormana Village, İbrad1, Antalya) were in the 'sandy clay' soil class. Furthermore, there were no differences in salinity among the values of the statistical test results. All soil samples were classified as 'non-saline' and 'very slightly saline'. An aggregation was present among the soils in terms of salinity. The EC values of the soil

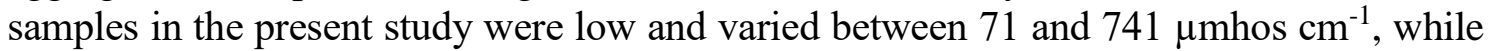
the highest EC value (741 $\mu$ mhos $\left.\mathrm{cm}^{-1}\right)$ was in $O$. armeniacum (C3: Mt. Termessos, Antalya) but the lowest EC value $\left(71 \mu\right.$ mhos $\left.\mathrm{cm}^{-1}\right)$ in $O$. narbonense (C3: The Çak1llı Passage, Cevizli, Akseki, Antalya). Most Ornithogalum species grew in slightly alkaline soils. In the present study, the $\mathrm{pH}$ values were in the range 6.9-8.3, and both the highest $\mathrm{pH}$ values (C: Mt. Güllük, Termessos, Antalya) and the lowest (C3: The Serinyaka Village, Gündoğmuş, Antalya) $\mathrm{pH}$ values were determined in O. armeniacum. No significant difference in soil reaction $(\mathrm{pH})$ existed among the species. The results demonstrated that the Ornithogalum species grew in soils with low to excess $\mathrm{CaCO}_{3}$ levels. There was a significant difference among the species $(\mathrm{P}<0.05)$. In terms of $\mathrm{CaCO}_{3}$, the soils of $O$. pamphylicum $(49.5 \%)$ were statistically quite different from the others $(\mathrm{P}<0.01)$. The averages of the $\mathrm{CaCO}_{3}$ contents of the species were very close to each other. O. montanum (13.2\%), O. neurostegium (10.3\%), O. umbellatum (21.8\%) and 
O. orthophyllum $(12.5 \%)$ grew in soils with a very high $\mathrm{CaCO} 3$ content. The soils, where $O$. lanceolatum (1.9\%), O. chetikianum (2.7\%), O. pyrenaicum (2.2\%) and $O$. oligophyllum (2.5\%) are grown had low $\mathrm{CaCO}_{3}$ values (Table 4). According to the average $\mathrm{CaCO}_{3}$ values, the soils belonging to $O$. pamphylicum were regarded as excess but the soils belonging to $O$. narbonense as low. In addition, the averages of the other species were in the 'medium' and 'very high' soil classes (Table 5). The species grew in soils mostly with high organic matter. There was no significant difference in organic matter among the soils of the species $(\mathrm{P}>0.05)$. However, the evaluation of the organic matter contents showed that the soils of $O$. oligophllum and $O$. orthophyllum contained high organic matter. Additionally, the soils of the other species had low to high organic matter contents (Table 4), and there were great variations among the organic matter contents (1.2 and 13.3\%) of the soil samples studied (Table 2), with the highest and the lowest organic matter contents recorded in O. oligophllum (C3: The Gembos Plateau, İbrad1, Antalya) and O. narbonense (C3: Yukar1 Karaman, Korkuteli, Antalya), respectively. No differences in phosphorus were present among the averages of the statistical test results. The phosphorus values of the soil samples were in the range 3.2$211.0 \mathrm{mg} \mathrm{kg}^{-1}$ (Table 2) and high in most of the soil samples (Table 4). In addition, both the highest (C3: Mt. Termessos, Antalya) and the lowest (C3: The Serinyaka Village, Gündoğmuş, Antalya) phosphorus values were found in $O$. armeniacum and the phosphorus values showed great variations (Tables 1 and 2). The Ornithogalum species grew in soils with high concentrations of potassium. According to the statistical tests, there was a significant difference in potassium among the species $(\mathrm{P}<0.05)$. According to the values, the species were included in various classes. For instance, potassium was medium and low in the soils of $O$. pamphylicum and $O$. chetikianum, whereas the soils of O. lanceolatum (657.5 mg kg-1) had the highest potassium values (Tables 3 and 4). The Ornithogalum species grew in soils with high concentrations of calcium. As the statistical tests showed, a significant difference in calcium was present among the species $(\mathrm{P}<$ $0.05)$. In terms of calcium, the soils of $O$. montanum $\left(6552 \mathrm{mg} \mathrm{kg}^{-1}\right)$ and $O$. pyrenaicum $\left(6046 \mathrm{mg} \mathrm{kg}^{-1}\right)$ were statistically quite different from those of the others. The averages of the calcium contents of the species were very close to each other, and the soil of $O$. pamphylicum (1825 mg kg $\mathrm{g}^{-1}$ ) had a medium concentration of calcium (Table 4). The Ornithogalum species grew in soils with high concentrations of magnesium. There was no significant difference in magnesium among the species according to the statistical tests ( $\mathrm{P}$ $>0.05)$. As a result of the evaluation of the averages, magnesium was found high in most of the species (Table 5). Moreover, the highest and the lowest averages of magnesium were determined in O. pyrenaicum $\left(746.8 \mathrm{mg} \mathrm{kg}^{-1}\right)$ and $O$. umbellatum $\left(300.5 \mathrm{mg} \mathrm{kg}^{-1}\right)$, respectively (Table 4).

\section{Discussion}

As a result, physical and chemical properties of the soil of natural Ornithogalum species have been determined, and the relationship between the plant and soil was evaluated in the present study. It is thought that the results will provide significant contributions to the cultivation studies regarding of Ornithogalum in its natural habitat.

The soil samples of the Ornithogalum species were mostly medium-textured (classified as 'loam' and 'sandy loam). Their salt contents were very low (non-saline); they were generally slightly alkaline; and their $\mathrm{CaCO}_{3}$ values ranged from low to excess. The organic matter contents showed great variability in the types of locality and varied 
between the 'low' and 'high' classes. Additionally, the P, K, Ca and Mg concentrations of the soil samples were generally high.

Soil texture affects many physical properties of soil such as the water-holding capacity, and the water infiltration rates. Sandy soils generally have high infiltration rates but poor water-holding capacity. All soil samples in the study were medium-textured; therefore, they had poor water infiltration rates and poor water-holding capacity. Soil texture influences the inherent fertility of soil as well. More nutrients can be absorbed by a gram of clay particles than by a gram of sand or silt particles, for the clay particles provide a much greater surface area for adsorption. Soil Samples 23, 24, 28, 30 and 32 had high Ca concentrations (8190, 7878, 8195, 7880, and 5880). According to Havlin et al. (2013), the $\mathrm{pH}$ values of soil samples are slightly alkaline. The level of acidity or alkalinity in a soil affects the availability of soil nutrients and the activity of soil micro-organisms and can affect the level of exchangeable nutrients. Soil Sample 9 had a lower $\mathrm{pH}$ value. $\mathrm{pH}$ affects the availability of nutrients to plants and can therefore be used to determine the production potential of the soil. $\mathrm{pH}$ preferences by plants can vary, though for most plants the desirable $\mathrm{pH}$ range is 6.0-6.5. At this level, microbial growth was also at the maximum level.

According to Dellavalle (1992), the EC levels become non-saline in the soil samples. Soil Sample 9 with a lower $\mathrm{pH}$ value had the highest EC level. Soil salinity affects a plant's uptake of water and nutrients and limits plant growth. The salt contents of all soil samples analyzed were low; thus, it was hard to evaluate the Ornithogalum species in terms of resistance to salt. The resistance of plants to calcium carbonate $\left(\mathrm{CaCO}_{3}\right)$ is one of the parameters which limit expansion and cultivation of natural plant species. Differences in the $\mathrm{CaCO}_{3}$ contents of the soils where the Ornithogalum species were grown were found among the varieties. The $\mathrm{CaCO}_{3}$ contents were high in the soils of the $O$. pamphylicum, $O$. armeniacum, $O$. umbellatum and $O$. narbonense varieties, low and medium in the soils of the $O$. lanceolatum, $O$. chetikianum, $O$. pyrenaicum and $O$. oligophyllum varieties, and very high in the soils of the $O$. orthophylum, O. neurostegium and $O$. montanum varieties.

Organic matter is a source of nutrients for plants besides being effective on the physical and chemical properties of soils. In general, organic matter content of soils that Ornithogalum species are grown was found to be high. The most interesting situation in organic matter content results is that the endemic species have the lowest organic matter content. O. pamphylicum (endemic) and O. chetikianum (endemic) were found to be grown in soils with low organic matter content, $O$. orthophylum in soils with high organic matter content, $O$. umbellatum, $O$. montanum, $O$. pyrenaicum and $O$. narbonense in soils with low to high organic matter content, $O$. armeniacum, $O$. neurostegium and $O$. oligophyllum in soils with medium to high organic matter content.

Phosphorus is essential in photosynthesis, and it is involved in energy transfer. It improves root development and rapid growth; encourages blooming; and increases resistance to diseases. An excess amount of phosphorus does not damage plants. Phosphorus also improves microbial activity in the soil. All soil samples had a high $\mathrm{P}$ value. Khan et al. (2016) showed that phosphorus significantly affected bulb volume and number of bulblets per plant, except the number of bulbs per plant in Polianthes tuberosa. Moreover, high phosphorus supply increased tuber biomass; however, it decreased the number of flowers per plant in Zantedeschia (Scagel and Schreiner, 2006). Furthermore, high phosphorus content reduced the number of flowers. This situation can be explained 
by the fact that phosphorus is extremely important as a structural element of many components, particularly nucleic acids and phospholipids.

Potassium plays a vital role in the physiological and biochemical functions of plants. It is absorbed in large amounts by plants. Moreover, it is used to build proteins; increases resistance to diseases by strengthening stalks and stems; increases the cuticle (waxy layer) to prevent water loss; helps prevent wilting; and enhances fruit size and development. According to Olsen and Sommers (1982), the potassium levels in the soil are adequate for the plant. According to Claassens (1990), the potassium requirements of Ornithogalum are low and the highest potassium levels do not significantly reduce the yield, but low potassium levels may reduce the probability of inconsistent yields. Bulbs of $O$. lanceolatum have a bigger size than the other species's bulbs. In our study, the highest phosphorus and potassium contents were obtained from the soils of the O. lanceolatum.

Calcium, which is an essential part of the plant cell wall structure, provides for normal transport and retention of other elements as well as strength in the plant. It is also considered to counteract the effect of alkali salts and organic acids within a plant. Ghoname et al. (2007) reported that calcium treatment to the plant from the soil significantly affected the plant length, fresh and dry weight however, in the vegetative stage, there was no significant effect on the diameter of the bulb. According to the results, $O$. pyrenaicum, $O$. narborense, $O$. montanum, species had the maximum flower stem lengths. Calcium contents of these species were also found to be high.

Magnesium is part of the chlorophyll in all green plants and essential for photosynthesis. It also helps activate many plant enzymes needed for growth. Gerandas and Fuhrs (2013) reported that the degradation of anthocyanins at high temperature decreased by $\mathrm{Mg}$ applications in ornamental plants. Anthocyanins are important constituents for specific colouration to flowers in ornamentals. Ornithogalum species are white in color. In this study, there was no significant difference between the Ornithogalum species and Mg contents.

\section{Conclusions}

The bulbs of $O$. nutans species are collected from the natural habitat and exported for ornamental and medicinal purposes in Turkey. In some cases, harvesting from nature is illegal for the species; nevertheless, the populations are in decline and are not cultivated. Therefore, cultivation and breeding studies are urgently needed. Natural distribution area should be taken into consideration when Ornithogalum sp. is cultivated. Understanding the relationship between certain soil properties and plant relation for Ornithogalum species, which have an economic value, can act as a guide for florists and botanists for a particular purpose.

Acknowledgements. This study was supported by the Scientific and Technological Research Council of Turkey (TÜBİTAK) (Project number: TOVAG 104 O 327).

\section{REFERENCES}

[1] Aykurt, C., Deniz, İ. G., Sar1, D., Vural, M., Sümbül, H. (2016): Resurrection of Ornithogalum brevipedicellatum (Asparagaceae) with morphological and molecular data. - Acta Bot. Croat. 75(1): 60-66. DOI: 10.1515/botcro-2016-0001. 
[2] Andric, A., Tubic, N. K., Rat, M., Vidakovic, D. O. (2015): Diversity and genetic structure of Ornithogalum L. (Hyacinthaceae) populations as revealed by RAPD-PCR Markers. - Genetika 47(1): 275-288. DOI: 10.2298/GENSR1501275A.

[3] Black, C. A. (1965): Methods of Soil Analysis. Part 2. - Amer. Society of Agronomy Inc., Madison, WI, pp. 1372-1376.

[4] Bouyoucos, G. J. (1951): A recalibration of the hydrometer method for making mechanical analysis of soil. - Agronomy J 43: 434-438.

[5] Brun, L. A., Maillet, J., Richarte, J., Hermannand, P., Remy, J. C. (1998): Relationships between extractable copper, soil properties and copper uptake by wild plants in vineyard soils. - Environ Pollut 102: 151-161.

[6] Claassens, A. S. (1990): The Nutrient Requirements of Ornithogalum and Lachenalia Two Indigenous South African Flowering Bulbs. - In: Beusichem, M. L. van (ed.) Plant Nutrition-Physiology and Applications, Springer, Dordrecht, pp. 649-652.

[7] Corominas, G. M., Azorín, M. M., Crespo, M. P. (2017): Confirmation of the presence of Ornithogalum umbellatum (Hyacinthaceae) in the Iberian Peninsula. - Anales del Jardín Botánico de Madrid 74(1): e049 2017. DOI: http://dx.doi.org/10.3989/ajbm.2437.

[8] Davis, P. H., Mill, R. R., Tan, K. (1988): Ornithogalum L. - In: Davis, P. H. (ed.) Flora of Turkey and the East Aegean Islands, Vol. 10. Edinburgh University Press, Edinburgh, UK, pp. 223-225.

[9] Dellavalle, N. B. (1992): Determination of Specific Conductance in Supertanat 1:2 Soil:Water Solution. - In: Handbook on Reference Methods for Soil Analysis. Soil and Plant Analysis Council, Inc. Athens, GA.

[10] Düşen, O., Deniz, İ. G. (2005): Ornithogalum sümbülianum (Hyacinthaceae), a new endemic species from South West Anatolia. - Pak J Bot 36: 33-36.

[11] Gerendás, J. Führs, H. (2013): The significance of magnesium for crop quality. - Plant and Soil 368(1-2): 101-128.

[12] Ghoname, A., El-Bassiony, A. M., Riad, G. S., Abd El-Baky, M. M. H. (2007): Reducing onion bulbs flaking and increasing bulb yield and quality by potassium and calcium application. - Australian Journal of Basic and Applied Sciences 1(4): 610-618.

[13] Goldblatt, P., Manning, J. C. (2011): A review of chromosome cytology in Hyacinthaceae subfamily Ornithogaloideae (Albuca, Dipcadi, Ornithogalum and Pseudogaltonia) in subSaharan Africa. - South African Journal of Botany 77: 581-591.

[14] Gomez, K. A., Gomez, A. A. (1984): Statistical Procedures for Agricultural Research. John Wiley and Sons Inc., New York.

[15] Jackson, M. C. (1967): Soil Chemical Analysis. - Prentice Hall of India Private Ltd., New Delhi.

[16] Kacar, B. (2009): Analysis of Soil. Second Edition. - Nobel Yayın Dağıtım Ticaret Yayın No: 44, Ankara.

[17] Kamanetsky, R., Okubo, H. (2012): Ornamental Geophytes: From Basic Science to Sustainable Production. - CRC Press, Boca Raton, FL.

[18] Kariuki, W., Kako, S. (2003): Micropropagation of Ornithogalum saundersiae Bak. Acta Hort 46(624): 521-526.

[19] Khan, S., Jan, I. Ullah, H., Iqbal, J. Iqbal, S., Shah, S. H. A., Khan, A. A. (2016): Influence of phosphorus and bulb size onflower and bulblet production of tuberose. American-Eurasian J. Agric. \& Environ. Sci. 16(1): 191-197. DOI: 10.5829/idosi.aejaes.2016.16.1.1285.

[20] Havlin, J. L., Tisdale, S. L., Nelson, W. L., Beaton, J. D. (2013): Soil Fertility and Fertilizers (8th Ed.). - Pearson Higher Ed, USA.

[21] Lii, T. S. C., Mazza, G. (1999): Correlations between leaf and soil mineral concentrations and ginsenoside contents in American Ginseng. - Hortscience 34: 85-87.

[22] Malabadi, R. B., Van Staden, J. (2004): Regeneration of Ornithogalum in vitro. - Afr J Bot 70: 618-621. 
[23] Manning, J. C., Forest, F., Devey, D. S., Fay, M. F., Goldblatt, P. (2009): A molecular phylogeny and a revised classification of Ornithogaloidea (Hyacinthaceae) based on an analysis of four plastid DNA regions. - Taxon 58: 77-107.

[24] Martinez-Azorin, M., Crespo, M. B., Juan, A. (2007): Taxonomic revision of Ornithogalum subg. Cathissa (Salisb.) Baker (Hyacinthaceae). - Anales del Jardín Botánico 64(1): 7-25.

[25] Mutlu, B., Karakuş, Ş. (2012): A new species of Ornithogalum (Hyacinthaceae) from East Anatolia, Turkey. - Turk J Bot 36: 125-133.

[26] Naik, P. K., Nayak, S. (2005): Different modes of plant regeneration and factors affecting in vitro bulblet production in Ornithogalum virens. - Sci Asia 31: 409-414.

[27] Nayak, S., Sen, S. (1995): In vitro propagation of Ornithogalum umbellatum through direct organogenesis. - Ind J Exp Bio 33: 144-146.

[28] Olsen, S. R., Sommers, L. E. (1982): P Availability Indices. P Soluble in Sodium Bicarbonate. - Page, A. L., Miller, R. H., Keeney, D. R. (eds.) Methods of Soil Analysis. Part 2. Chem. and Microb. Propert. American Society of Agronomy, Soil Science Society of America, Madison, WI, pp. 404-430.

[29] Ozel, Ç. A., Khawar, K. M. (2007): In vitro bulblet regeneration of Ornithogalum oligophyllum E. D. Clarke Using twing scale bulb explants. propagation of ornamental plants. - Propag Ornamental Plants 7: 82-88.

[30] Rapp, M., Santa Regina, I., Ricoand, M., Gallego, H. A. (1999): Biomass, nutrient content, litter fall and nutrient return to the soil in Meditterranean oak Forest. - Forest Ecol Manage 119: 39-49.

[31] Rat, M. M., Gavaric, N. S., Kladar, N. V., Andric, A. M., Anackov, G. T., Bozin, B. N. (2016): The Phenolics of the Ornithogalum umbellatum L. (Hyacinthaceae): Phytochemical and Ecological Characterization. - Chem Biodivers 13(11): 1551-1558. DOI: 10.1002/cbdv.201600090.

[32] Reed, C. (2011): Plants for Places. - Dorling Kindersley Ltd., UK.

[33] Roca-Perez, L., Boluda, R., Perez-Bermudez, P. (2004): Soil-plant relationships, micronutrient contents, and cardenolide production in natural populations of Digitalis obscura. - J Plant Nutr Soil Sci 167: 79-84.

[34] Saatçi, N., Yağmur, B. (2000): Relationships between the concentrations of iron, macro and micronutrients in satsuma mandarine leaves (Citrus reticulata Blanco). - J Plant Nutr 23: $1745-1750$.

[35] Scagel, C. F., Schreiner, R. P. (2006): Phosphorus supply alters tuber composition, flower production, and mycorrhizal responsiveness of container-grown hybrid Zantedeschia. Plant and Soil 283: 323-337.

[36] Uysal, T., Ertuğrul, K., Dural, H. (2005): A new species of Ornithogalum (Liliaceae) from South Anatolia, Turkey. - Bot J Linnean Soc 148: 501-504.

[37] Yanagawa, T., Ito, I. (1988): Differences in the capacity for bulblet regeneration between bulb scale explants excised from different parts of Ornithogalum bulbs. - J Jap Soc Hort Sci 57: 454-461.

[38] Y1lmaz, G. (2014): Seed micromorphology of Ornithogalum refractum and Ornithogalum fimbriatum (Hyacinthaceae) from Turkey. - Biological Diversity and Conservation 7(2): $110-114$.

[39] Ziv, M., Lilien-Kipnes, H. (2000): Bud regeneration from inflorescense explants for rapid propagation of geophytes in vitro. - Plant Cell Rep 19: 845-850.45. 